\title{
Pharmacological Therapy for Myocardial Infarction in the EIderly. An 8-year Analysis
}

\author{
Márcia Regina Pinho Makdisse, Andrea de M. Matsushita, Iran Gonçalves Júnior, Odete Miranda, \\ Ana Cristina Gomes, Monica M. Cartocci, Silvia Covre, Antonio Carlos de Camargo Carvalho
}

\author{
São Paulo, SP - Brazil
}

\begin{abstract}
Objective - To assess the changes in the medicamentous treatment of elderly patients hospitalized with acute myocardial infarction occurring over an 8-year period.

Methods - We retrospectively analyzed 379 patients above the age of 65 years with acute myocardial infarction who were admitted to the coronary unit of a universityaffiliated hospital from 1990 to 1997. The patients were divided into 2 groups, according to the period of time of hospital admission as follows: group 1 -from 1990 to 1993; and group 2-from 1994 to 1997.
\end{abstract}

Results - The use of beta-blockers $(40.8 \% \times 75.2 \%$, $p<0.0001)$ and angiotensin-converting enzyme inhibitors $(42 \%$ x $59.5 \%, p=0.001)$ was significantly greater in group 2, while the use of calcium antagonists $(42 \% x$ $18.5 \%, p<0.0001)$ and general antiarrhythmic drugs $(19.1 \% \times 10.8 \%, p=0.03)$ was significantly lower. No significant difference was observed in regard to the use of acetylsalicylic acid, thrombolytic agents, nitrate, and digitalis in the period studied. The length of hospitalization was shorter in group 2 (13.4 18.9 days $x 10.5 \pm 7.5$ days, $p<0.001)$. The in-hospital mortality was $35.7 \%$ in group 1 and $26.6 \%$ in group $2(p=0.07)$.

Conclusion - Significant changes were observed in the treatment of elderly patients with acute myocardial infarction, with a greater use of beta-blockers and angiotensin-converting enzyme inhibitors and a lower use of calcium antagonists and antiarrhythmic drugs in group 2. The length of hospitalization and the mortality rate were also lower in group 2, even though the reduction in mortality was not statistically significant.

Key words: myocardial infarction, elderly, treatment

Universidade Federal de São Paulo - Escola Paulista de Medicina Mailing address: Márcia Regina Pinho Makdisse-Rua Dr. Franco da Rocha, 205/51 05015-040 - São Paulo, SP, Brazil - E-mail: marciamakdisse@yahoo.com English version by Stela Maris C. e Gandour
Cardiovascular disease is the major cause of mortality in the population above the age of 65 years ${ }^{1}$. In Brazil, according to the Pan-American Health Organization and the World Health Organization (1994), cardiovascular disease accounts for $50.3 \%$ of the deaths in the population above the age of 50 years, acute myocardial infarction being its major cause ${ }^{2}$.

The treatment of acute myocardial infarction has undergone significant changes over the past 30 years, with a progressive decrease in mortality from $30 \%$ to 4 to $7 \%$ in properly treated patients ${ }^{3-6}$. In elderly patients, however, mortality still remains elevated, ranging from $17.5 \%$ to $41 \%^{7-11}$.

The factors accounting for the higher mortality and morbidity of elderly patients have not been totally defined. The intrinsic cardiovascular alterations related to the aging process are believed to leave the elderly with a lower functional reserve to deal with the complications caused by acute myocardial infarction. In addition, a higher number of associated diseases, of diagnostic difficulties, and of differences in the therapeutical approach exist ${ }^{12-15}$.

In the elderly, a trend in a reduced use of drugs like beta-blockers, acetylsalicylic acid, and thrombolytic agents with proved efficacy in treating myocardial infarction has been shown in several studies that assessed the use of these medications in clinical practice ${ }^{16-21}$.

Several factors have been related to this reduced use, such as the fear of adverse reactions, the presence of comorbidities increasing the contraindications, the diagnostic difficulties that delay treatment onset, and also the fact that the elderly have been excluded from or little represented in most studies that assess the drugs used in the treatment of acute myocardial infarction ${ }^{22,23}$.

Therefore, this study aimed to assess the changes in the therapeutical approach for elderly patients admitted to a university-affiliated hospital in the acute phase of myocardial infarction during an 8-year period.

\section{Methods}

We retrospectively studied 379 patients above the age 
of 65 years in the acute phase of myocardial infarction, who were consecutively admitted to the coronary unit of the Hospital São Paulo affiliated with the Escola Paulista de Medicina of the Universidade Federal de São Paulo for a period of 8 years (from 1990 to 1997). Their ages ranged from 65 to 94 (mean of 73.5) years. Most patients (55.7\%) were males. The medical records of all patients were carefully reviewed, and the criterion used to diagnose myocardial infarction was the presence of at least 2 of the following findings: suggestive clinical picture, electrocardiographic and enzymatic alterations. When necessary, we used additional data derived from the radioisotopic study with technetium pyrophosphate, echocardiography, and autopsy. No patient was excluded from the study.

The patients were divided into 2 groups according to the time of hospitalization, and we assessed changes in drug prescription and in clinical evolution during the period analyzed. Group 1 consisted of 157 patients with a mean age of $73.3 \pm 7.03$ years (ranging from 65 to 94) who were consecutively hospitalized from 1990 to 1993; group 2 consisted of 222 patients with a mean age of $73.8 \pm 6.51$ years (ranging from 65 to 90 ) who were consecutively hospitalized from 1994 to $1997(\mathrm{p}=0.46)$. The groups showed no statistically significant differences in regard to age, sex, functional class at hospital admission, infarct location, antecedents of arterial hypertension, diabetes mellitus, previous heart disease, and previous infarction. The only difference observed was the higher prevalence of non-Q-wave infarction in group 2 (tab. I).

The numerical variables were analyzed using the Student $t$ test for comparison between the groups. The analysis of the qualitative variables was performed with the chi-square test $\left(\mathrm{X}^{2}\right)$, and in the cases where it could not be used, the Fisher exact test was performed. The statistical significance level adopted was $5 \%(\mathrm{p}<0.05)$.

\begin{tabular}{|c|c|c|c|c|}
\hline \multicolumn{5}{|c|}{$\begin{array}{l}\text { Table I - Clinical and demographic characteristics of } 379 \text { elderly } \\
\text { patients hospitalized with myocardial infarction from } 1990 \text { to } 1997\end{array}$} \\
\hline Variables & $\begin{array}{c}\text { Total } \\
\mathrm{n}=379\end{array}$ & $\begin{array}{c}\text { Group 1 } \\
(1990-93) \\
n=157\end{array}$ & $\begin{array}{c}\text { Group 2 } \\
(1994-97) \\
n=222\end{array}$ & $\mathrm{p}$ \\
\hline \multicolumn{5}{|l|}{ Sex } \\
\hline $\begin{array}{l}\text { Male } \\
\text { Female }\end{array}$ & $\begin{array}{l}211(55.7 \%) \\
168(44.3 \%)\end{array}$ & $\begin{array}{l}84(53.5 \%) \\
73(46.5 \%)\end{array}$ & $\begin{array}{l}127(57.2 \%) \\
95(42.8 \%)\end{array}$ & 0.541 \\
\hline \multicolumn{5}{|l|}{ Functional class } \\
\hline $\begin{array}{r}\text { Killip I - II } \\
\text { III - IV }\end{array}$ & $\begin{array}{c}316(83.4 \%) \\
63(16.6 \%)\end{array}$ & $\begin{array}{c}133(84.7 \%) \\
24(15.3 \%)\end{array}$ & $\begin{array}{l}183(82.4 \%) \\
39(17.6 \%)\end{array}$ & 0.654 \\
\hline \multicolumn{5}{|l|}{ Infarction location } \\
\hline $\begin{array}{l}\text { Anterior } \\
\text { Nonanterior }\end{array}$ & $\begin{array}{l}158(41.7 \%) \\
221(58.3 \%)\end{array}$ & $\begin{array}{l}69(43.9 \%) \\
88(56.1 \%)\end{array}$ & $\begin{array}{l}89(40.1 \%) \\
133(59.9 \%)\end{array}$ & 0.519 \\
\hline \multicolumn{5}{|l|}{ Antecedents } \\
\hline Previous heart disease & $80(21.1 \%)$ & $31(19.7 \%)$ & $49(22.1 \%)$ & 0.675 \\
\hline Diabetes mellitus & $118(31.1 \%)$ & $54(34.4 \%)$ & $64(28.8 \%)$ & 0.298 \\
\hline Hypertension & $232(61.2 \%)$ & $91(57.9 \%)$ & $141(63.5 \%)$ & 0.324 \\
\hline Previous infarction & $51(13.5 \%)$ & $17(10.8 \%)$ & $34(15.3 \%)$ & 0.267 \\
\hline Non-Q-wave infarction & $61(16.0 \%)$ & $17(10.8 \%)$ & $44(19.8 \%)$ & $0.027 *$ \\
\hline
\end{tabular}

\section{Results}

The major drugs used in the elderly patients during hospitalization are shown in table II. The patients in group 2 , who were more recently treated, received proportionally more beta-blockers $(40.8 \% \times 75.2 \%, \mathrm{p}<0.0001)$ and angiotensin-converting enzyme inhibitors $(42 \% \times 59.5 \%, \mathrm{p}=0.001)$ than the patients in group 1 . No significant difference was observed in regard to the intravenous use of beta-blockers between the groups $(31.3 \%$ x 39.5\%, $\mathrm{p}=0.311)$.

We also observed a significantly lower use of calcium antagonists in group $2(42 \% \times 18.5 \%, \mathrm{p}<0.0001)$. In regard to the type of calcium antagonist used, nifedipine was used significantly less $(42.4 \%$ x $12.2 \%, \mathrm{p}<0.002)$ and diltiazem significantly more in group $2(57.6 \% \times 85.4 \%, \mathrm{p}=0.005)$.

The use of antiarrhythmic drugs was also significantly lower in group 2, both in the prophylactic (10.8\% x 1.3\%, $\mathrm{p}<0.001)$ and global (therapeutic and prophylactic) $(19.1 \% \mathrm{x}$ $10.8 \%, \mathrm{p}=0.03$ ) forms.

No significant statistical difference between the groups was observed in the use of acetylsalicylic acid $(87.3 \% \mathrm{x}$ $92.3 \%, \mathrm{p}=0.14)$, thrombolytic agents $(43.9 \% \times 43.7 \%$, $\mathrm{p}=0.95)$, nitrate $(82.8 \% \times 86.5 \%, \mathrm{p}=0.4)$, and digitalis $(26.1 \% \mathrm{x}$ $18.9 \%, \mathrm{p}=0.12$ ).

The mean length of hospitalization was significantly lower in group $2(13.4 \pm 8.9$ days $\times 10.5 \pm 7.5$ days, $p=0.0007)$, which also had a lower in-hospital mortality, even though this difference has not reached statistical significance $(35.7 \% \times 26.6 \%, \mathrm{p}=0.07)$.

\section{Discussion}

Age is an independent predictor of mortality after acute myocardial infarction, which makes the elderly patients a high-risk group for complications and mortality ${ }^{24,25}$. Therefore, they have the highest potential for therapeutic benefit

\begin{tabular}{|c|c|c|c|c|}
\hline \multicolumn{5}{|c|}{$\begin{array}{l}\text { Table II- Medications used in elderly patients in the acute phase of } \\
\text { myocardial infarction }\end{array}$} \\
\hline Medication & $\begin{array}{c}\text { Total } \\
\mathrm{n}=379\end{array}$ & $\begin{array}{c}\text { Group 1 } \\
(1990-93) \\
n=157\end{array}$ & $\begin{array}{c}\text { Group } 2 \\
(1994-97) \\
n=222\end{array}$ & $\mathrm{p}$ \\
\hline Acetylsalicylic acid & $342(90.2 \%)$ & $137(87.3 \%)$ & $205(92.3 \%)$ & 0.14 \\
\hline Calcium antagonists & $107(28.2 \%)$ & $66(42 \%)$ & $41(18.5 \%)$ & $<0.0001 *$ \\
\hline Nifedipine & $33(30.8 \%)$ & $28(42.4 \%)$ & $5(12.2 \%)$ & $0.002 *$ \\
\hline Diltiazem & $73(68.2 \%)$ & $38(57.6 \%)$ & $35(85.4 \%)$ & $0.005 *$ \\
\hline Verapamil & $1(0.9 \%)$ & 0 & $1(2.4 \%)$ & \\
\hline \multicolumn{5}{|l|}{ Antiarrhythmic drugs } \\
\hline Global & $54(14.2 \%)$ & $30(19.1 \%)$ & $24(10.8 \%)$ & $0.03 *$ \\
\hline Prophylactic & $20(5.3 \%)$ & $17(10.8 \%)$ & $3(1.3 \%)$ & $<0.001$ \\
\hline \multicolumn{5}{|l|}{ Beta-blockers } \\
\hline Total & $231(60.9 \%)$ & $64(40.8 \%)$ & $167(75.2 \%)$ & $<0.0001 *$ \\
\hline Intravenous & $86(37.2 \%)$ & $20(31.3 \%)$ & $66(39.5 \%)$ & 0.31 \\
\hline Digitalis & $83(21.9 \%)$ & $41(26.1 \%)$ & $42(18.9 \%)$ & 0.12 \\
\hline ACE inhibitor & $198(52.2 \%)$ & $66(42 \%)$ & $132(59.5 \%)$ & $0.001 *$ \\
\hline Nitrate & $322(84.9 \%)$ & $130(82.8 \%)$ & $192(86.5 \%)$ & 0.4 \\
\hline Thrombolytic agent & $166(43.8 \%)$ & $69(43.9 \%)$ & $97(43.7 \%)$ & 0.95 \\
\hline
\end{tabular}


resulting from the use of medication that has been proved to reduce mortality after acute myocardial infarction, such as beta-blockers, acetylsalicylic acid, and angiotensin-converting enzyme inhibitors. However, in clinical practice, we observe a tendency toward the lower use of these drugs in elderly patients.

In the present study, a retrospective 8-year analysis of 379 elderly patients hospitalized with acute myocardial infarction, the medicamentous treatment prescribed in the first 4 years (group 1) was compared with that prescribed in the last 4 years (group 2). No statistically significant differences were observed between the 2 groups in regard to age, sex, functional class at admission, infarct location, antecedents of arterial hypertension, diabetes mellitus, previous heart disease, and previous infarction. A significant difference was only observed in regard to the presence of non-Q-wave infarction, which was higher in group 2 . The demographic characteristics reported as poor-prognostic factors after acute myocardial infarction were as follows: age $>60$ years, female sex, Q-wave infarction, diabetes mellitus, and previous infarction ${ }^{26}$.

The prevalence of non-Q-wave acute myocardial infarction increases with age. Gurwitz et $\mathrm{al}^{27}$ showed an $8.2 \%$ rate of non-Q-wave acute myocardial infarction in patients below the age of 55 years, $10.4 \%$ for patients between 55 and 64 years, $13.7 \%$ between 65 and 74 years, $16.7 \%$ between 75 and 84 years, and $18.4 \%$ above 85 years. Data from the Framingham Study have shown that in-hospital mortality due to non-Q-wave acute myocardial infarction is lower than that observed in transmural acute myocardial infarction; long-term mortality, however, is similar because of the high risk of reinfarction in these patients ${ }^{28}$.

Significant differences in drug prescription were observed in the periods analyzed. A significant increase in the use of beta-blockers was observed in the last 4 years analyzed. The global rate of use of these drugs increased from $40.8 \%$ in group 1 to $75.2 \%$ in group $2(p<0.0001)$. Comparing these results with data in the literature, the rate of betablocker use observed in the last years studied is very high. In a retrospective study of 369 patients with acute myocardial infarction, Brandt et al ${ }^{29}$ observed that only $27.7 \%$ of the elderly received beta-blockers during hospitalization. It seems that a certain fear exists in regard to the intravenous use of beta-blockers, because the awaited proportional increase in their global use did not occur $(31.3 \%$ x $39.5 \%$, $\mathrm{p}=\mathrm{NS}$ ). The use of beta-blockers has been recommended in the acute phase of acute myocardial infarction for all patients when contraindications do not exist ${ }^{30-31}$. Studies assessing the use of these drugs in acute myocardial infarction have shown a more significant reduction in mortality in elderly patients ${ }^{32-36}$.

The use of angiotensin-converting enzyme inhibitors was also higher in group 2 , which was more recently treated $(42 \%$ x $59.5 \%, \mathrm{p}=0.001)$. Some studies have shown a reduction in mortality with the use of these drugs in acute myocardial infarction, mainly in the presence of infarction of the anterior wall and signs of heart failure ${ }^{37,38}$. The SAVE trial
(1992) showed a $13 \%$ reduction in mortality in patients aged from 56 to 64 years and a $25 \%$ reduction in mortality in patients above 65 years ${ }^{39}$. Malone et al ${ }^{40}$, in a study that assessed the differences in treatment after acute myocardial infarction according to age, reported that the use of angiotensin-converting enzyme inhibitors increased with age, from $17 \%$ in younger patients to around $30 \%$ in elderly patients, due to the higher frequency of heart failure in the latter patients.

In regard to calcium antagonists, their use significantly dropped from $42 \%$ to $18.5 \%$ in the last 4 years studied $(p<0.0001)$. A change in the type of calcium antagonist prescribed during hospitalization was observed. The use of nifedipine was significantly lower, while a proportional increase in the use of diltiazem, usually indicated as a substitute for the beta-blocker or after transluminal coronary angioplasty, was observed. The studies assessing the use of calcium antagonists in the treatment of acute myocardial infarction showed no benefits, and, in some cases, even showed a deleterious effect $\mathrm{t}^{41-44}$. The ACC/AHA Guidelines for the Management of Patients with Acute Myocardial Infarction and the guidelines of the Brazilian Society of Cardiology (SBC) do not recommend the routine use of those drugs after acute myocardial infarction. This is due to the fact that, even in the case of non-Q-wave acute myocardial infarction, no evidence exists that calcium antagonists, especially diltiazem and verapamil, are more beneficial than beta-blockers are ${ }^{30,31,45}$. Short-acting nifedipine is contraindicated in the acute phase of myocardial infarction because it has a negative inotropic effect and causes reflex sympathetic activation.

The use of antiarrhythmic drugs in acute myocardial infarction, especially lidocaine, underwent significant changes in the past decade, prior to which it was routinely used for ventricular fibrillation prophylaxis. The more recent recommendations, however, limit its use to the treatment of potentially fatal arrhythmias. A meta-analysis published in 1988 showed a trend in higher mortality in the group receiving prophylactic lidocaine, despite the $33 \%$ reduction in the ventricular fibrillation rate ${ }^{46}$. In our study, the more recently treated group used significantly lower amounts of antiarrhythmic drugs during hospitalization, both in the prophylactic and global forms $(10.8 \% \times 1.3 \%, \mathrm{p}<0.001$ and $19.1 \%$ x $10.8 \%, \mathrm{p}=0.03$, respectively).

We observed no difference between the groups in regard to the use of acetylsalicylic acid, thrombolytic drugs, nitrate, and digitalis. The mean global rate of use of acetylsalicylic acid was $90.2 \%$. We considered the rate of use of acetylsalicylic acid in our study to be adequate, because, despite the recommendation for this drug to be routinely used in acute myocardial infarction due to its effect on mortality reduction at a low cost and good tolerability, some studies still show its lower use in elderly patients. In a recent analysis of 5,490 patients above 65 years of age hospitalized with acute myocardial infarction, only $76 \%$ of the patients with no contraindications received acetylsalicylic acid during hospitalization ${ }^{47}$. 
The mean global rate of use of thrombolytic drugs in our study was $43.8 \%$. The use of these drugs in elderly patients is controversial. An analysis of the 9 major studies comparing thrombolysis and placebo in acute myocardial infarction shows a higher proportional reduction in mortality in nonelderly patients. In the elderly patients, the proportional reduction in mortality is statistically significant up to the age of 74 years; above this age, an absolute reduction in mortality is still observed (10 lives spared per 1,000 patients treated). However, hemorrhagic complications, mainly cerebral stroke, are more frequently found in elderly patients and are more associated with the use of r-TPA and APSAC; therefore, streptokinase should be used instead 48 . Gurwitz et a ${ }^{49}$, studying the use of thrombolytic drugs and age in 350,755 patients, reported that the rate of their use was inversely proportional to age as follows: $51 \%$ in patients $<55$ years, $43.6 \%$ in patients from 55 to 65 years, $33 \%$ from 65 to 75 years, and $19 \%$ in patients above 75 years. A recent study assessed the efficacy of the reperfusion therapy (thrombolysis and primary angioplasty) in 39,212 elderly patients, using data from the Cooperative Cardiovascular Project ${ }^{50}$. The results showed that the elderly patients with acute myocardial infarction who received those 2 types of reperfusion therapy had a lower mortality rate after a 1 -year follow-up than did the control group.

The mean global rate of use of nitrate in the present study was high $(84.9 \%)$. Nitrate has been recommended to improve persistent ischemia, heart failure, and hypertension after acute myocardial infarction, because no significant reduction in mortality occurred with its routine use in acute myocardial infarction ${ }^{30,31,37}$.

Only $21.9 \%$ of the patients received digitalis during hospitalization. The use of digitalis in acute myocardial infarction has been recommended for select patients with su- praventricular tachyarrhythmias associated with heart failure or heart failure refractory to the use of angiotensin-converting enzyme inhibitors and diuretics ${ }^{30}$.

In regard to length of hospitalization, a significant difference was observed between the groups (group 2 had a shorter length of hospitalization). This reduction in the length of hospitalization may be related to the more adequate therapeutic regimen used in that group; however, it may also have resulted from the changes in our service in the past few years, which may have sped up the performance of tests and procedures, allowing earlier hospital discharge.

A not significant tendency toward lower mortality was observed in group $2(35.7 \%$ and $26.6 \%, \mathrm{p}=0.07)$. The size of the sample and the limitations of a retrospective study have limited the analysis of mortality, which remained undoubtedly high in the elderly patients.

The changes in the treatment of elderly patients with acute myocardial infarction observed in this study resulted from the standardization of the management adopted at the coronary unit of the Hospital São Paulo based on the results of multicenter studies and on the recommendations of the ACC/AHA Task Force and the guidelines of the Brazilian Society of Cardiology ${ }^{30,31}$. We observed that, despite the correct use of the drugs recommended by the national and international guidelines, mortality in the elderly remains very high, suggesting that a more aggressive treatment after acute myocardial infarction may cause a greater impact on the improvement of ventricular function and on mortality in this group of patients. Therefore, randomized studies assessing the efficacy of therapeutic interventions are required, especially in elderly patients older than 75 years, because this group has been systematically excluded from most studies already performed.

\section{References}

1. Kannel W, Gordon T. Evaluation of cardiovascular risk in the elderly: the Framingham Study. Bull NY Acad Med 1978; 54: 573-91.

2. Organizacion Panamericana de la Salud \& Organizacion Mundial de la Salud: Las Condiciones de Salud en las Americas. Publicacion Cientifica ${ }^{\circ}$ 549, vol.II, Washington, 1994:87-100.

3. Henning H, Covell J, Swan E, O'Rourke R, Ross Jr J. Prognosis after acute myocardial infarction: a multivariate analysis of mortality and survival. Circulation 1979; 59: 1124-36.

4. McGovern P, Folsom A, Sprafka M, et al. Trends in survival of hospitalized myocardial infarction patients between 1970 and 1985: the Minnesota Heart Survey. Circulation 1992; 85: 172-9.

5. Maynard C, Weaver D, Litwin P, etal. Hospital mortality in acute infarction in the era of reperfusion therapy: The MITI(Myocardial Infarction Triage and Intervention) Project. Am J Cardiol 1993; 72:877-82.

6. Naylor C, Chen E. Population-wide mortality trends among patients hospitalized for acute myocardial infarction: the Ontario Experience 1981 to 1991. J Am Coll Cardiol 1994; 24: 883-6

7. Latting C, Silverman M. Acute myocardial infarction in hospitalized patients over age 70. Am Heart J 1980; 100: 311-8.

8. Polanczyk C, Prado K, Borges M, Ribeiro J. Infarto do miocárdio na era trombolítica: elevada mortalidade em pacientes idosos. Rev Assoc Med Brasil 1993; 39:65-72.
9. Normand S, Glickman N, Sharma R, McNeil B. Using admission characteristics to predict short-term mortality from myocardial infarction in elderly patients: results form the Cooperative Cardiovascular Project. JAMA 1996; 275: 1322-8.

10. Udvarhelyi I, Gatsonis C, Epstein A, Pashos C, Newhouse J, McNeil B. Acute myocardial infarction in the Medicare population: process of care and clinical outcomes. JAMA 1992; 268: 2530-6.

11. Pashos C, Newhouse J, Mcneil B. Temporal changes in the care and outcomes of elderly patients with acute myocardial infarction, 1987 through 1990. JAMA 1993;270: 1832-6.

12. Port S, Cobb F, Coleman R, Jones R. Effect of age on the response of the left ventricular ejection fraction to exercise. N Engl J Med 1980; 303: 1133-7.

13. Harris R, Piracha A. Acute myocardial infarction in the aged: prognosis and management. J Am Geriatr Soc 1970; 18: 893-904.

14. Tofler G, Muller J, Stone P, et al and The MILIS (Multicenter Investigation of the Limitation of Infarct Size) study group. Factors leading to shorter survival after acute myocardial infarction in patients aged 65 to 75 years compared with youngerpatients. Am JCardiol 1988; 62:860-7.

15. Wei J. Age and the cardiovascular system. N Engl J Med 1992; 327: 1735-9.

16. McLaughlin T, Soumerai S, Willison D, et al. Adherence to national guidelines for treatment of suspected acute myocardial infarction: evidence for undertreatment in women and the elderly. Arch Intern Med 1996; 156: 799-805.

17. Karlson B, Herlitz J, Hjalmarson A. Impact of clinical trials on the use of beta 
blockers after acute myocardial infarction and its relation to other risk indicators for death and 1-year mortality rate. Clin Cardiol 1994; 17:311-6.

18. Viskin S, Kitzis I, Lev E, et al. Treatment with beta-adrenergic blocking agents after myocardial infarction: from randomized trials to clinical practice. J Am Coll Cardiol 1995; 25: 1327-32.

19. Gurwitz J, Goldberg R, Chen Z, Gore J, Alpert J. Beta-blocker therapy in acute myocardial infarction: evidence for underutilization in the elderly. Am J Med 1992; 93:605-10.

20. Gurwitz J, Gore J, Goldberg R, Rubison M, Chandra N, Rogers W. Recent age-related trends in the use of thrombolytic therapy in patients who have had acute myocardial infarction. Ann Intern Med 1996; 124: 283-91.

21. Krumholz H, Radfor M,Ellerbeck E, et al. Aspirin for secondary prevention after acute myocardial infarction in the elderly: prescribed use and outcomes. Ann Intern Med 1996; 124: 292-8.

22. Chest Pain Study Group. Comparison of clinical presentation of acute myocardial infarction in patients older than 65 years of age to younger patients: the Multicenter Chest Pain Study Experience. Am J Cardiol 1989; 63: 772-6.

23. Gurwitz J, Nananda F, Avorn, J. The exclusion of the elderly and women from clinical trials in acute myocardial infarction. JAMA 1992, 268: 1417-22.

24. MahonNG,CoddMB, O'RorkeC, etal. Management and outcome of acutemyocardial infarctioninolderpatientsinthethrombolyticera.J Am Geriatr Soc 1999;47:291-4

25. Montague TJ, Ikuta RM, Wong RY, et al. Comparison of risk and patterns of practice in patients older and younger than 70 years with acute myocardial infarction in a two-year period (1987-1989). Am J Cardiol 1991; 68: 843-7.

26. Stevenson R, Ranjadayalan K, Wilkinson P, Roberts R, Timmis AD. Short and long term prognosis of acute myocardial infarction since introduction of thrombolysis. Br Med J 1993; 307: 349-53.

27. GurwitzJH, Gore JM, Goldberg RJ, Rubison M, Chandra N, Rogers WJ. Recent age-related trends in the use of thrombolytic therapy in patients who have had acute myocardial infarction. Ann Intern Med 1996; 124: 283-91.

28. Berger CJ, Murabito JM, Evans JC, Anderson KM, Levy D. Prognosis after first myocardial infarction: comparison of Q-wave and non-Q-wave myocardial infarction in the Framingham Heart Study. JAMA 1992; 268: 1545-51.

29. Brandt C, Wees-Ponchon A, Nisand G, et al. Survie dans l'infarctus du myocarde au stade aigu dans un group de 369 patients admis consécutivement entre 1988 et 1992: analyse des facters de risques et de la pratique médicale. Arch Mal Couer 1994; $87: 861-8$

30. ACC/AHA Guidelines for the management of patients with acute myocardial infarction. A report of the American College of Cardiology/American Heart Association Task Force on Practice Guidelines (Committee on Management of Acute Myocardial Infarction). American Heart Association Website, 1999

31. II Diretriz da Sociedade Brasileira de Cardiologia para o Tratamento do Infarto Agudo do Miocárdio. Arq Bras Cardiol 2000; 74(supl. II): 1-46.

32. Hjalmarson A, Herlitz J, Malek I, et al. The Göteborg Metoprolol Trial: effect on mortality of metoprolol in acute myocardial infarction. Lancet 1981;2:823-7.

33. BHAT (Beta-Blocker Heart Attack) Study Group. A randomized trial of propranolol in patients with acute myocardial infarction: mortality results. JAMA 1982;247: 1707-14

34. Norwegian Multicenter Study Group. Timolol-induced reduction in mortality and reinfarction in patients surviving acute myocardial infarction. NEngl $\mathrm{J}$ Med 1981;304:801-7.

35. The MIAMI(Metoprolol in Acute Myocardial Infarction) trial research group. A randomized placebo-controlled international trial. Eur Heart J 1985; 6: 199-226.

36. ISIS-1(First International Study of Infarct Survival) collaborative group. Randomized trial of intravenous atenolol among 16,027 cases of suspected acute myocardial infarction. Lancet 1986; 2: 57-66.

37. ISIS-4 collaborative group. A randomized factorial trial assessing early oral captopril, oral mononitrate, and intravenous magnesium sulphate in $58,050 \mathrm{pa}-$ tients with suspected acute myocardial infarction. Lancet 1995; 345: 669-85.

38. GISSI-3 (Gruppo Italiano per lo Studo della Sopravvivenza nell'Infarto Miocardico). Effects of lisinopril and transdermal glyceryl trinitrate singly and together on 6-week mortality and ventricular function after acute myocardial infarcion. Lancet 1994; 343: 1115-22.

39. PfefferMA, Braunwald E, Moye LA, et al. Effect of captopril on mortality and morbidity in patients with left ventricular dysfunction after myocardial infarction results of the Survival And Ventricular Enlargment Trial. N Engl J Med 1992; 327:669-77.

40. Malone Ml, Sial SH, Battiola RJ, Nachodsky JP, Solomon DJ, Goodwin JS. Agerelated differences in the utilization of therapies post acute myocardial infarction. J Am Geriatr Soc 1995; 43: 627-33.

41. Wilcox RG, Hampton JR, Banks DC, et at. Trial of early nifedipine in acute myocardial infarction: the TRENT study. BrMed J 1986; 293: 1204-8.

42. The Israeli Sprint Study Group. Secondary Prevention Reinfarction Israeli Nifedipine Trial(SPRINT): a randomized intervention trial of nifedipine in patients with acute myocardial infarction. Eur Heart J 1988; 9: 354-64.

43. Effect of verapamil on mortality and major events after acute myocardial infarction The DAVIT (Danish Verapamil Infarction Trial) II. Am JCardiol 1990; 66: 779-85.

44. The Multicenter Diltiazem Postinfartion Trial (MDPIT) Research Group. The effect of diltiazem on mortality and reinfarction after myocardial infarction. NEngl JMed 1988; 319:385-92.

45. Yusuf S, Wittes J, Probstfield J. Evaluating effects of treatment in subgroups of patients within a clinical trial: the case of non-Q-wave myocardial infarction and beta-blockers. Am J Cardiol 1990; 66:220-2.

46. MacMahon S, Collins R, Peto R, Koster RW, Yusuf S. Effects of prophylactic lidocaine in suspected acute myocardial infarction: an overview of results from the randomized, controlled trials. JAMA 1988;260:1910-6.

47. KrumholzH, Radford M,EllerbeckE, et al. Aspirin for secondary prevention after acute myocardial infarction in the elderly: prescribed use and outcomes. Ann Intern Med 1996; 124: 292-8

48. Fibrinolytic Therapy Trialists' Collaborative Group. Indications for fibrinolytic therapy in suspected acute myocardial infarction: collaborative overview of early mortality and major morbidity results from all randomized trials of more than 1,000 patients. Lancet 1994; 343:311-22.

49. Gurwitz J, Gore J, Goldberg R, Rubison M, Chandra N, Rogers W. Recent age-related trends in the use of thrombolytic therapy in patients who have had acute myocardial infarction. Ann Intern Med 1996; 124: 283-91.

50. Berger AK, Radford MJ, Wang Y, Krumholz HM. Thrombolytic therapy in older patients. J Am Coll Cardiol 2000;36:366-74. 